\title{
La narrativa educacional chilena y su proceso de transformación reciente: un análisis sociológico-histórico ${ }^{1}$
}

\author{
The Chilean educational narrative and its process of \\ recent transformation: a historical-sociological analysis
}

Javier Corvalán²

\section{Resumen}

A partir de un concepto de narrativa educacional y de un enfoque proveniente de la sociología de la educación, este artículo analiza el rol del Estado en el desarrollo educativo chileno así como los procesos sociales y políticos que se han establecido para trasformar y refundar esta narrativa. Se sostiene que hasta la actualidad se mantiene una narrativa que le da una centralidad al Estado pese a los intentos por privatizar y descentralizar el sistema educacional, así como de regularlo desde una lógica de mercado.

\section{Palabras clave:}

Sociología de la educación, narrativa educacional, Chile.

\section{Abstract}

From an educational narrative approach and a conceptual framework stemming from the sociology of education, the article analyzes the State's role in the Chilean educational development as well as the social and political processes that have been established to transform and redefine this narrative. It is argued that, up until now, a narrative that gives centrality to the State, despite attempts to privatize and decentralize the educational system as well as regulate it based on market logic, remains.

Keywords:

Sociology of education, educational narrative, Chile

Artículo recibido el 19 de junio de 2012 y aprobado el 8 de febrero de 2013

1 Documento producido en el marco del Programa de Investigación Políticas Públicas, Equidad e Igualdad del Sistema Educacional, financiado por la Fundación Ford.

2 Universidad Alberto Hurtado, Santiago, Chile. Correo electrónico: jcorvala@cide.cl 


\section{Introducción: sistemas educacionales modernos: integración, selección y movilidad social}

Más allá de su objetivo de transmisión del conocimiento especializado a las generaciones siguientes, la educación en las sociedades contemporáneas, organizada en sistemas educacionales complejos y masivos, es una concreción material y simbólica, impulsada por diversos sectores, con el fin de democratizar la sociedad. Tal democratización busca hacer accesible, al conjunto de la población, un cierto conocimiento y vivencia común que permita tanto la integración de la sociedad como también una clasificación y selección de individuos, acorde a los principios democráticos y a las necesidades de división social del trabajo imperantes en una sociedad moderna. Adicionalmente, los sistemas educacionales modernos buscan aportar decisivamente a la movilidad social de los individuos y mediante ella, a la estabilidad de la sociedad.

Por un lado, la integración social es un requisito funcional básico de cualquier sociedad y a la vez es de importancia aún mayor debido a la heterogeneidad y diferenciación creciente de las sociedades contemporáneas. Por otro lado, la selección y clasificación de los individuos a partir de sus habilidades y talentos es una necesidad imperiosa de las sociedades complejas y en particular del sistema laboral. Por último, la movilidad social es, desde el punto de vista del individuo, una de las concreciones de la idea democrática en las sociedades modernas y, por tanto, constituye también un elemento fundamental para la estabilidad de las mismas.

La creciente secularización, producto de la modernidad tardía y del liberalismo naciente, aceleró y complejizó los procesos de diferenciación social y cultural, razón por la cual al interior de las sociedades contemporáneas se desarrolló la coexistencia de individuos y grupos sociales con orientaciones valóricas y creencias no solo distintas sino también contrapuestas. Diversos intelectuales de fines del siglo XIX y comienzos del $\mathrm{XX}^{3}$ avizoraron la situación problemática que emergía de la conjunción de un proceso de secularización, diferenciación y de heterogeneidad axiológica creciente y se plantearon la pregunta respecto de la posibilidad de sobrevivencia de la sociedad y de un mundo en orden si los individuos no compartían un mínimo trasfondo valórico y de orientación conductual que posibilitara la integración, la convivencia y la sintonía entre las expectativas individuales y la acción colectiva. Si bien es cierto, parte importante de las respuestas a este dilema han apelado a la acción del Estado como ente integrador, la respuesta, particularmente después de la segunda mitad del siglo XIX, ha sido todavía mucho más contundente aludiendo a lo indispensable de una instrucción o enseñanza común y universal, garantizada desde el poder de Estado, es decir, no solo proponiendo a tal instrucción como un derecho sino también como un deber de los ciudadanos.

El funcionamiento de las sociedades modernas supone que mediante esta escolaridad universal -garante de una socialización mínimamente igualitaria- se aporta al mandato de integrar la sociedad haciendo que individuos diversos y distintos tengan un mínimo de vivencias, aspiraciones y racionalidades comunes 4 y que, al mismo tiempo, tal proceso sea un redistribuidor potencial de los grados de poder adquiridos a parir del mérito individual.

Por los elementos mencionados, particularmente la integración y la movilidad social, pero sobre todo por este último, la educación, en su versión

3 Entre los cuales se encuentra Durkheim (1990), así como también Saint Simon (que ve la necesidad de la planificación centralizada como soporte frente a la creciente disociación social y económica), Comte (que ve en el predominio del pensamiento científico la defensa contra el desorden social creado por la revolución francesa) y Spencer (que ve una evolución natural de la sociedad en el plano social y moral como respuesta a una momentánea falta de unidad de los individuos), entre otros pensadores clásicos de la sociología

4 Tal vez el aporte teórico inicial más importante a este respecto, más a allá de Durkheim, es el de Parsons y su modelo AGIL que da cuenta de los cuatro imperativos funcionales de todo sistema social: A: adaptación; G: capacidad para alcanzar metas (goal attainment); I (integración); L (latencia) (ver Parsons 1988). 
pública y masificada del siglo XX, se constituyó en una aspiración progresista y político-liberal estructurada a partir de un principio de igualdad y de re-distribución de un conocimiento que había sido generado, inicialmente, en espacios privados y elitistas de la sociedad. En efecto, la historia del conocimiento anterior a la universalización de la educación es un ejemplo de cómo la ciencia, el arte y la cultura sofisticada se han producido, transmitido y conservado al interior de algunos circuitos sociales, siendo de paso tal limitación un elemento fundamental para controlar el poder en la sociedad5. La consagración de los sistemas educativos modernos tiende a cuestionar ese funcionamiento y desde la lógica de la estructura global de tales sistemas esto se refleja en tanto ellos pretenden que un cierto tipo de saber transite desde una categoría de bien privado a una de bien público, responsabilizando al Estado por este proceso. Es por ello que la historia de la educación moderna es indiferenciable del desarrollo de los Estados modernos y de la identificación de estos últimos con la ampliación de la igualdad civil y política (cf. Archer 1984).

En el caso de Chile, si bien es cierto se puede considerar que existe una idea de educación pública desde poco después de la Independencia, es en el siglo XX, y más específicamente su segunda mitad, cuando la educación se identifica plenamente con el

5 Es este el tema que enuncia Bourdieu con los conceptos de distinción social y de consumo de bienes culturales y simbólicos dentro de los cuales está la educación y su certificación (Bourdieu y Passeron, 1970; Bourdieu, 1979). La tesis bourdiana se refiere al hecho que los procesos de masificación educativa generan el acceso a bienes simbólicos y a un cierto tipo de consumo cultural que hasta hace unas décadas estaba reservado a las élites sociales. Mientras se produce lo anterior, las antiguas élites y también las nuevas que se van consolidando por la misma redistribución generan nuevas distinciones de consumo cultural a medida que los sectores sociales emergentes acceden a tal consumo, en particular, a la educación. El acceso masivo a los sistemas educacionales genera, por tanto, en estas sociedades, un doble movimiento de democratización del conocimiento y de certificación, por un lado, y de desplazamiento de las élites en búsqueda de nuevas distinciones, por otro. Sin embargo mientras el sistema educativo mantenga su contenido y organización pública, las élites no podrán apropiarse de manera absoluta de nuevos conocimientos por lo que el saldo neto sería positivo a favor de la democratización del saber. proceso de democratización social creciente y se le ve como un objetivo central del mismo (cf. Egaña, 2000; PIIE, 1984). Respecto de los tempranos orígenes de una idea de educación pública en el país, $y$ tal como lo señala Barros Arana (1902), uno de los pioneros de la historiografía chilena, en 1817 el gobierno independentista recién instaurado desarrolla en Santiago y mediante su gobernador-intendente un reglamento para "la multiplicación de escuelas públicas, la reforma en los métodos de enseñanza, la elección de maestros y directores idóneos para la educación de la juventud" (p. 212).

Por su parte, Serrano (1994), al analizar los fundamentos ideológicos de los independentistas al comienzo de tal proceso, señala algunos aspectos que coinciden con el fundamento que Durkheim, casi un siglo más tarde, daría a la educación y a la responsabilidad del Estado sobre ella:

La educación debía ser pública para crear vínculos entre los habitantes de un mismo territorio, es decir, debía formar una cierta homogeneidad que pasaba por el poder centralizador del Estado. Continuando con la misma lógica del Estado absolutista, los patriotas no dudaron del derecho que tenía para ejercer este control, que no era concebido como antagónico a la educación privada y menos a la religiosa (pp. 41-42).

El mismo Barros Arana (1902) indica que poco más tarde, en 1830, las ambiciones de instrucción pública se mantienen pero que su realización se ve dificultada por razones diversas:

al sancionarse en setiembre de 1830 la devolución de los bienes raíces secuestrados a las congregaciones relijiosas, se había dispuesto que todas estas abriesen una escuela de primeras letras en cada pueblo en que tuviesen una casa conventual. Se pasaron, sin embargo, cerca de dos años sin que se diera cumplimiento a esa disposición. Por fin, el Ministerio del Interior, declarando la insuficiencia de los recursos del Estado para atender en la medida de sus deseos este ramo del servicio mandó de la manera más perentoria, por un decreto de 12 de julio de 1832, que esas escuelas fueran establecidas en el término de un 
mes bajo apercibimiento de que, de no hacerlo así, las establecerían las municipalidades respectivas de cuenta de los conventos i bajo la más estricta responsabilidad (p. 252).

La acción gubernamental en educación aumentó notoriamente en el periodo 1840-1860 con diversas iniciativas dentro de las que destaca la fundación de la Universidad de Chile (1842) y la promulgación de la Ley General de Instrucción Primaria de 1860, entre otras6. Esta última señala en su artículo 10. que: "la instrucción primaria se dará bajo la dirección del Estado" y en su artículo 2o. garantiza materialmente lo anterior: "la instrucción que se diere en virtud de esta ley será gratuita y comprenderá a las personas de uno y otro sexo" (Larraín y Larraín, 1871, p. 490). La Universidad de Chile, por su parte, nació con una importante tuición sobre el sistema escolar, particularmente en la educación secundaria, mandato que se ejercía a partir del monopolio de la examinación 7 .

Tal proceso de consolidación educativa a partir de la acción estatal -asumimos en este artículo- requirió necesariamente de un consenso social al interior de las élites económicas, políticas y culturales y de cuyas decisiones dependió no solo la ampliación de la educación pública, sino también la extensión de este beneficio a los sectores medios y populares, destinatarios y beneficiarios potenciales de tal expansión. Por lo anterior, la educación públicamente considerada puede ser concebida al mismo tiempo que un conjunto de dispositivos legales, como un discurso o relato que vive de manera permanente en el imaginario de los individuos, al referirse a sus

6 "La década de 1840 fue pródiga en la fundación de instituciones educacionales que venían a complementar con enseñanza vocacional la estructura madre de la educación primaria, secundaria y superior. Las más importantes tenían por objeto estructurar socialmente el sistema en su conjunto fueron la Escuela Normal de Preceptores (1842) y la Escuela de Artes y Oficios (1849). Ambas eran a los sectores populares que accedían a la educación primaria, lo que la educación secundaria y superior a las clases dirigentes". (Serrano, 1994, p. 81).

7 “La Ley Orgánica de 1842 en su artículo 15 establecía que los exámenes anuales de los colegios estatales y particulares de Santiago debían rendirse ante comisiones nombradas por las facultades. Ese era el requisito legal para ingresar a los estudios superiores". (Serrano, 1994, p. 223). ventajas y a su importancia para la vida colectiva e individual. Este discurso es también mantenido y avalado por los poderes públicos a partir de su producción simbólica que se concretiza tanto en mensajes como en programas y políticas educativas, y por supuesto, en el imperativo legal que proclama la obligatoriedad de la escolarización.

En las páginas que siguen abordamos tal problemática para un periodo particular de la historia educacional chilena. Se trata de la enorme transformación que el sistema educacional experimentó en la pasada década de 1980 que en gran parte perdura hasta nuestros días. Consideramos que, como lo explicaremos más adelante, el sistema educacional consolidado hasta los años 1970 en Chile era productor a la vez que producto de lo que algunos autores han llamado una narrativa educacional, es decir, un relato que articula el sentido de qué y cómo es legítimo tal sistema y en torno a qué mediaciones institucionales y a qué discursos debe ser estructurado.

Como otro principio de análisis, en este texto asumimos que en el siglo XX se llevó a cabo en Chile un proceso de consolidación de una narrativa educacional que sustentó la existencia y legitimidad pública del sistema educativo mismo. La mayor expresión reciente de esta narrativa es, a nuestro parecer, la reforma educacional de 1965 que sintetiza requerimientos y discursos provenientes del campo político (ampliación de la cobertura como expansión y consolidación de la democracia), intelectual (cambios en planes y programas como concreción de una nueva relación entre el conocimiento y la ciudadanía) y técnico (integración de nuevas modalidades pedagógicas), como lo señala un estudio histórico que aborda tal proceso:

"la reforma educacional de 1965-70 es un esfuerzo orgánico y comprensivo de cambio que combina tres áreas: la rápida ampliación e igualación de las oportunidades educativas, la modernización y mejoramiento de las prácticas escolares y la adecuación del desarrollo educacional a los cambios económico-sociales y políticos que se intentaron en este periodo bajo el signo de una revolución en libertad". (PIIE, 1984, p. 21). 
Esta narrativa educacional ha sido tensionada como consecuencia de los enormes cambios estructurales del sistema educativo chileno comenzados a inicios de los $80^{8}$. Insistimos en que tal proceso de transformación no es solo cuantitativo sino, sobre todo, cualitativo, ya que en tal período el sistema educativo se empieza a estructurar sobre un nuevo discurso de legitimidad.

Como ya señalamos, este discurso o narrativa educacional tuvo en Chile, hasta los años 1980, un referente matriz en torno a la noción de educación pública, provista por el Estado y con características extramercantiles y centralizadoras. Por tanto parece ajustado señalar que esta narrativa de la educación chilena pueda ser denominada como centro-estatista. Ella se refiere al protagonismo de un actor central, el Estado, en la provisión y regulación de la demanda educativa y en las características de su oferta. Prácticamente todo el proceso educativo incremental entre los años 1940 y 1970 comienza y converge en el actor estatal y en una homogeneidad y férreo control que este hace de las características de la oferta educacional. Tales características no fueron exclusivas del sistema educativo sino que, por el contrario, corresponden a una concepción global de desarrollo de la sociedad en la cual el protagonismo de la acción estatal, en una versión centralizada, es visto como requisito fundamental de un desarrollo social con equilibrio democrático. En este discurso, el sector educacional privado es asumido como legítimo, en tanto receptor de fondos estatales, si está subordinado a estrictos controles y regulaciones de su accionar, tal como se observa con la aprobación de la ley de subvenciones escolares a establecimientos privados a comienzos de los años 1950:

La educación particular, si bien atiende una proporción menor de la matrícula, se ve favorecida por el sistema de subvenciones estatales acordado por ley en 1951. Esto significa que los establecimientos privados que se benefician de ellas deben aplicar los planes y programas oficiales y

8 Respecto a la comparación socioeducativa de las reformas de 1965 y 1980 cf. Brunner, 1980. someterse a la supervigilancia del sector público como condición necesaria para recibir subsidios. (PIIE, 1984, p. 18).

La transformación de los años 1980 afectó precisamente esa narrativa centro-estatista, pues fue cuando se produjo un proceso que intentó legitimar de manera más profunda el rol de la educación privada y en especial a los agentes privadosubvencionados destinados a proveerla (Ruiz, 2010). Paralelamente, a partir de esa transformación se introdujeron regulaciones de mercado para gestionar y proveer mayor eficacia en el sistema educacional. En este proceso se observa un intento por refundar una nueva narrativa educacional, a la que podríamos denominar de mercado o competitiva9. Este intento fundacional de un nuevo discurso o narrativa educacional va a encontrar un importante soporte en los años 1980, pero sobre todo en la década de 1990, en la teoría del capital humano que ve a la educación principalmente como un proceso individual con consecuencias colectivas agregadas y como un sistema necesariamente subordinado a la estructura ocupacional y productiva de los países (Becker, 1983).

Este panorama de transformaciones no es tampoco externo a la influencia y legitimidad de las disciplinas a partir de las cuales se concibe y planifica la política educativa antes y después de los años 1980. De esta manera, en el periodo anterior a la transformación a la que hacemos referencia, el

9 Las denominaciones que hemos escogido para estas narrativas obedecen a características y proyectos centrales de las mismas. La narrativa centro-estatista basa su visión de la educación como bien público a partir de la generación y distribución que el Estado hace del mismo. La educación privada, sea ella subvencionada o no, es, en esta perspectiva, un elemento secundario y minoritario que para muchos de sus aspectos claves debe también basarse en los mandatos del Estado. Un segundo elemento es la visión homogenizadora de la narrativa centro-estatista como producto de un Estado de bienestar social de mediados del siglo XX. En contrapartida, la narrativa de mercado o competitiva asume que el sistema educativo es fundamentalmente un escenario de disputa de recursos y, por consiguiente, competitivo. Como todo mercado se presupone que las características de la oferta deben estar estructuradas desde la demanda lo que significa que la "forma" que tenga el sistema educativo (número y tipo de establecimientos, por ejemplo) es un proceso que debe concretarse de acuerdo al tipo de demanda y cantidad en que ella se produzca. 
incipiente desarrollo de las ciencias sociales en el país y el peso aún menor de las mismas en la planificación educativa particularmente entre las décadas de 1940 a la de 1970, hacen que el sistema educativo sea pensado desde el campo político y, a partir de los años 1960, desde las nacientes disciplinas de la planificación social (cf. Ministerio de Educación, 1961, 1964). Con todo, aquí se quiere reafirmar que a partir del proceso de expansión y consolidación de educación al amparo del Estado centralizado, el sistema educacional es principalmente asumido como una estructura que es consecuencia de la acción política y que, por tanto, responde principalmente a los macro procesos de democratización constante de la sociedad. Ello explica que, como ya lo señalamos, el principal elemento de evaluación de logro del sistema educativo sea en ese momento el aumento constante de la cobertura ya que la misma es vista al interior de la narrativa centro-estatista como la concreción del aporte de tal sistema a la democratización creciente y a la integración de la sociedad.

La transformación de fines de los años setenta y comienzos de los ochenta modifica esta perspectiva e introduce a la economía neoliberal como la principal e incluso única disciplina capaz de generar lenguaje explicativo y analítico del sistema educativo ${ }^{10}$. La versión del neoliberalismo adoptada en Chile para construir una nueva narrativa del sistema educacional tiene al menos tres componentes fundamentales: i) como lo señalamos anteriormente, utiliza la teoría del capital humano como principal referente teórico para comprender el rol de la educación en la sociedad. A partir de esta teoría, el sistema educativo es

10 Este predominio de la economía sobre las restantes ciencias sociales corresponde incluso a una política de Estado frente a análisis de todo el orden social como lo constata Garretón (2005): "como adelantamos, la economía cobra gran protagonismo dentro de las ciencias sociales, expandiéndose en recursos y estudiantes, por el rol que juega en el proyecto del régimen militar de instalar un modelo neo-liberal de desarrollo que reemplace al modelo basado en el Estado y en la industrialización, y por su aporte a la ideología oficial que combina doctrina militar, filosofía política integrista y discurso económico neo-liberal" (p. 14). También señala: "en el plano universitario, la Ley de Universidades consagra un deterioro de las ciencias sociales, en la medida que solo la economía es definida como exclusivamente universitaria, el resto podía ser enseñado por instituciones no universitarias" (p. 10). concebido como una respuesta funcional al sistema productivo orientado aquel, fundamentalmente, en una regulación de mercado (Bonal, 1998). ii) Con lo anterior, la educación es entendida, además, como un tipo de acción individual basado en la racionalidad y en el cálculo del individuo (Becker, 1983). iii) Los dos elementos anteriores implican que para sincerar correctamente el sistema educativo y llegar a su óptimo funcionamiento y acoplamiento con el sistema productivo y el mercado del trabajo, es imperioso estructurarlo como un mercado abierto, es decir, limitando fuertemente sus regulaciones y permitiendo que la asignación que se le haga de recursos refleje la eficiencia productiva de sus unidades.

Sin embargo, en este panorama de transformaciones, los actores que protagonizan el sistema educativo no necesariamente asimilan ni aceptan el cambio que se impone a las estructuras organizativas y políticas del mismo sistema, ni muchos menos tales actores asumen fácilmente la legitimidad de la nueva narrativa. Particularmente los docentes, en la mayor parte de los países que han experimentado transformaciones educacionales aceleradas, desarrollan una lógica defensiva puesto que, como lo ha indicado la literatura pertinente al caso chileno (cf. Núñez, 1989), su identidad está construida en torno al Estado-docente y por tanto a partir de la narrativa centro-estatista.

El concepto de narrativa educacional ha sido propuesto por el académico sueco Sverker Linbald y por el investigador norteamericano Thomas Popkewitz (Linblad y Popkewiz, 2001, 2004). Recientemente ambos autores han definido la narrativa educacional como una manera de

pensar cómo aspectos de la realidad están formados mediante distinciones y categorías que circulan en la política pública y en las declaraciones de los actores educacionales. Las narrativas educacionales son historias de salvación. Las políticas y las investigaciones sobre las reformas escolares son narraciones sobre cómo salvar o distribuir la nación mediante la educación de los niños (p. 71)." 
Más adelante, los mismos autores se refieren a la narrativa educacional como articulada en torno a una historia de progreso junto a la de salvación, lo cual se comunica como algo beneficioso para el individuo y para la sociedad. También la narrativa, según estos autores, es una suerte de historia de redención, puesto que "la saga del progreso es contada mediante un sistema político que es continuamente vigilante mediante el trabajo hacia una sociedad totalmente inclusiva"(p.72). De esta manera, la narrativa educacional alude necesariamente a la constitución identitaria de la educación en la sociedad y a las expectativas y creencias que los actores depositan en ella.

Los mismos autores se refieren al concepto de narrativa aplicado a lo educacional como una noción útil para comprender las transiciones educacionales, específicamente como ciertas historias "son construidas en relación a las escuelas y los niños y su vinculación con algún sentido colectivo de progreso y finalidad". En esta línea, es interesante cómo los autores citados relacionan una cierta funcionalidad de la narrativa educacional con lo que Benedict Anderson (1993) denomina comunidades imaginadas. De manera similar y en una reflexión cercana aún cuando no relacionada directamente con educación sino con procesos identitarios de las sociedades latinoamericanas, el sociólogo chileno Jorge Larraín (2005) alude también a Anderson señalando que "una identidad nacional es un puro artefacto cultural, una comunidad imaginada como lo ha descrito Anderson, un sentido de fraternidad que vive en la mente de sus miembros (...) las identidades nacionales son discurso, narrativas sobre el ser nacional" (p. 162). Larraín analiza, desde el punto de vista de la identidad nacional, un tema que tiene un claro paralelo con nuestra temática educacional y que se refiere a narrativas en competencia. La pregunta que nos hacemos es si ha sucedido algo similar en el campo estrictamente educativo, es decir, si ha existido un trasfondo que bien puede ser identitario respecto de la educación, particularmente en su versión pública y de responsabilidad estatal y si ella ha experimentado similares procesos de refundación y de competencia.

\section{La generación de la narrativa centro-estatista y su intento de transformación en Chile}

Uno de los mayores logros institucionales del Chile republicano y democrático fue su sistema educacional. En efecto, como consecuencia de los procesos de democratización y de participación social y política desencadenados durante el siglo XX, se desarrolló con fuerza un sistema educativo propiamente tal, que incluyó escuelas, liceos y universidades. De acuerdo con el modelo centralizado que había marcado la administración política del país y del modelo de industrialización estado-desarrollista que se consagra hacia mitad del siglo XX, el sistema escolar fue concebido con una lógica también centro-estatista en la cual una administración central -el Ministerio Educación- era no solo la gestora sino también la propietaria de un extenso conglomerado de instituciones escolares, formando así una red de educación republicana, laica y gratuita (Núñez, 1998). La tónica de este sistema escolar fue su diseño homogéneo, por lo cual la mayoría de los niños chilenos eran formados en una rutina escolar relativamente similar ${ }^{11}$. También y desde los inicios del sistema escolar, existía un sector de escuelas privadas-subvencionadas que estaban, por lo general, vinculadas a la iglesia católica. Por último existía, al igual que hoy en día, un sector de establecimientos educativos particulares y privados, que recibían una pequeña proporción de la matrícula nacional (Corvalan, Elacqua y Salazar, 2010).

El golpe militar de 1973 y el posterior Régimen Militar cambiaron fuertemente este panorama, no de manera inmediata sino en especial a partir de los años ochenta, tal como fue reseñado en las primeras páginas de este artículo. Así, el Régimen Militar desarrolló una política pública diferenciada en las décadas de 1970 y 1980. En la primera, su accionar tanto en educación como en otros campos, se fundamentó en la represión política y en un severo ajuste económico que se llevó a cabo mediante la

11 En sociología escolar este tema ha sido abordado desde Durkheim a Bourdieu aludiendo a la incorporación de un habitus en los alumnos a través de la práctica escolar, plasmada en la rutina, tema que con algunas variantes teóricas lo retoma Dubet mediante el concepto de experiencia escolar. 
reducción del Estado y de la minimización de su accionar político-público:

en relación al periodo anterior, en el lapso 19761978, se observa cierta persistencia en el discurso sobre el "sistema nacional de educación" y en la preservación del aparato educacional del Estado y de su rol como regulador y planificador. Se acentúa el discurso de prioridad a la atención de los sectores de extrema pobreza y sobre eliminación de los factores de desigualdad en la distribución de los beneficios educativos. (PIIE, 1984, p. 78).

A comienzos de los años ochenta, el gobierno comenzó lo que se ha llamado una fase fundacional (Garretón, 1983) destinada a crear una nueva institucionalidad cuyos principios son el apoliticismo como centro ideológico de la vida de los individuos y el mercado como elemento articulador preferencial de la vida pública. La educación no escapó a este proceso y su institucionalidad fue profundamente transformada durante esa década. Para entender la lógica de tal proceso de transformaciones es necesario incorporar a los principios antes mencionados, al proyecto de descentralización de servicios públicos que, en términos reales, fue más bien lo que se conoce como una desconcentración de la provisión de salud y de educación.

Los documentos y estudios que existen sobre las transformaciones educativas de la época nos sirven para fundamentar la lógica argumentativa de las mismas de la manera siguiente:

1. El sistema educativo chileno existente hasta el año 1973 es considerado politizado en exceso. Si bien este juicio se hace principalmente en relación a las universidades, también alcanza el mundo escolar y en particular al gremio docente. El proyecto de descentralizacióndesconcentración cumple con el objetivo de aportar a esta despolitización ya que, entre otros aspectos, rompe con la unidad sindical de los docentes. El discurso de la época señala que los objetivos políticos sectoriales atentan contra el objetivo de unidad nacional que es propio de un sistema educacional. De esta manera, el proyecto de sistema educacional del gobierno militar recoge la exigencia de construcción del Estado-nación que había sido propio de la narrativa fundacional de tal sistema, pero la contrapone al funcionamiento del sistema político y a la heterogeneidad de ideas, propias de tal sistema: "la municipalización representa también un instrumento eficaz en lo que llamábamos la privatización del conflicto social [...] los conflictos que, como se demostrará, en el pasado comprometían al profesorado, involucraban necesariamente a la misma cúpula de Estado" (PIIE, 1984, pp. 52-53; cf. Espinoza y González 1993).

2. La necesidad y conveniencia de una participación ciudadana local en contraposición a lo que se denomina una participación política. Esto se reconoce en el hecho de que, al ser administradas por los municipios, las escuelas generarían una mayor sintonía y comunicación con la comunidad y lo que a su vez enmarcará la conversación educativa entre las familias y los agentes locales en aquello que es estrictamente educativo. Este tema no deja de ser interesante puesto que, a diferencia de lo señalado en el punto anterior, hay aquí una alusión a los aspectos microsociales de la educación y una crítica a su vinculación macrosocial-política del periodo anterior ${ }^{12}$.

3. Una mayor eficiencia en el gasto y en la asignación de los recursos. Este es el principal argumento de sintonización de la lógica de mercado con exigencias hechas al sistema educativo bajo el subentendido de una asignación ineficiente de los recursos mediante la estructura centralizada. Los argumentos respecto de este tema no dejan de ser paradojales

12 Por ejemplo el documento El Ladrillo que da cuenta de los principios fundamentales del Régimen Militar en materia de ordenamiento económico y social, al referirse a las bondades de un proceso de descentralización educativa señala: "uno de los sectores más ineficientes del sector público es el área de la educación donde, aparte del extremo burocrático, no existen mecanismos para que el usuario del servicio (padres y alumnos) puedan controlar la calidad y el tipo de educación que se está implantando [...] las limitadas experiencias de los últimos años, que han resultado en una mayor participación de los padres y profesores en la administración de escuelas y liceos, han sido exitosas" (CEP, 1992, pp. 148-149). 
dado que aún cuando lo señalado constituye un juicio técnico, no se citan estudios de referencia al respecto ${ }^{13}$.

4. Por último, se alude a una mayor participación del sector privado debido a una eventual incapacidad del sector estatal de asumir la demanda creciente de educación y se posibilita la obtención de lucro mediante la oferta educativa privada con subvención del Estado. A diferencia de los anteriores, se trata este de un argumento fundamentalmente técnico aun cuando conlleva evidentes impactos sociales y políticos. En efecto, con ello se reconoce explícitamente aquí el proyecto de reducción del gasto fiscal al mismo tiempo que un aumento constante de la cobertura escolar ${ }^{14}$.

Los cuatro elementos anteriores pueden ser considerados como los antecedentes para llevar a cabo la transformación en cuestión y, como se observa, son tanto técnicos como políticos. Lo interesante es describir también cuáles son los aspectos de política educativa que se reservan para el Estado dentro del nuevo ordenamiento y entre ellos se señala:

a. La tuición sobre los contenidos de la enseñan$\mathrm{za}$, partiendo de verdades fundamentales que deben ser transmitidas y mediante las cuales se preserva el "humanismo cristiano, que se expresa en la Declaración de Principios de la Junta de Gobierno de Chile" (El Mercurio, 1979). Es importante recordar que este

13 El mismo texto aludido en la cita anterior señala: "se estima que la forma más adecuada de abaratar el costo y mejorar la calidad de la educación es una drástica descentralización de la actual estructura de manera que sea la comunidad local quien pasa a administrar la unidad escolar respectiva" (CEP, 1992, p. 148).

14 Podemos citar al respecto la "Entrevista de El Mercurio al ministro Gonzalo Vial" del 8 de marzo de 1979: “... pero se da entrada al lucro en educación (pregunta del entrevistador). Por de pronto no solo al lucro. Mucha educación privada es gratuita o semigratuita... No toda. Dicho sea de paso, es religiosa; muchas laica o neutra. Uno de los esfuerzos privados más grandes y fecundos de nuestra historia educacional lo hizo la Sociedad de Instrucción Primaria cuya orientación puede decirse fue radical. Y tampoco el lucro en la educación es en sí censurable, si la educación es buena y si hay educación gratuita para quienes la necesitan. Precisamente consolidar este último objetivo es lo que exige el Estado, para enfocar hacia él la totalidad de sus recursos, alentar al mismo tiempo la enseñanza privada". proyecto de control de contenidos curriculares, bastante paradójico al interior de un ordenamiento educativo y socioeconómico fuertemente liberal, se debe probablemente a los motivos expresados por el mismo general Pinochet en una entrevista de la época en la que se refiere a que tanto la libertad curricular como la autonomía del profesor pueden tener resultados subversivos: "La educación en estos momentos está concebida en tal forma que abre las puertas a la acción sibilina del marxismo soviético. Me he dado el trabajo de leer algunos de los programas de educación y mi primera impresión es que ellos dejan tal libertad que permiten al maestro marxista guiar al muchacho en la dirección que él desea. El profesor puede tener la libertad para decidir cómo desarrolla las clases y cómo pasa las materias; pero es el Estado que tiene que decidir cuáles materias se pasarán, orientando los programas conforme a los intereses vocacionales que demanda el país" (El Mercurio, 1980).

b. La responsabilidad estatal por el acceso universal a la educación básica (primaria), considerando un privilegio el acceso a la educación media (secundaria) y superior. Como lo señala uno de los principales análisis del periodo, esta limitación de responsabilidad estatal y de garantía ciudadana "representa una importante restricción al principio de igualdad de oportunidades que prevaleciera en el pasado" (PIIE, 1984, pp. 50-51). Respecto de la educación superior El Ladrillo señala:

Los niveles superiores de educación -técnica y profesional- representan un beneficio directo y notorio para los que lo obtienen, de modo que no se justifica en absoluto la gratuidad de este tipo de educación; de hecho, ni siquiera se justifica el subsidio parcial que hoy reciben pues a él acceden principalmente a los grupos de mayor poder económico. (CEP, 1992, p. 146). 
Se consagra una autolimitación del alcance del Estado en educación, fundamentalmente en torno a funciones normativas y fiscalizadoras, otorgando en contrapartida espacio para el mercado y la iniciativa privada:

El Estado, a través del Ministerio de Educación, solo tendría a su cargo la formulación de la política general, el control de los requisitos mínimos de promoción y currículum y la obligación de financiar el costo mínimo de cada uno que se estuviese educando; para ello traspasaría a las municipalidades los fondos respectivos para que estos centros comunales los administraran. El Estado podría otorgar subsidios especiales a determinadas regiones o centros específicos que por su naturaleza necesitaren para ello un servicio adecuado. (CEP, 1992, p. 149).

De lo anterior ¿qué es posible concluir como continuidad y cambio de una narrativa educacional proveniente del desarrollo democrático de Chile durante el siglo XX, a partir de los cambios introducidos a comienzos de los años ochenta? En cuanto a elementos de continuidad de este discurso articulador entre Estado y sociedad sobre educación, se encuentran ${ }^{15}$ :

i. La idea de la educación como instrumento de igualdad de oportunidades en sociedades profundamente desiguales. En ningún momento se renuncia a este principio orientador ${ }^{16}$ aun cuando se le separa de la idea de educación pública y se le acerca al concepto de mérito individual y, en consecuencia, de igualdad inicial y potencial desigualdad posterior. Este principio recorre gran parte de las políticas públicas de la época señalando que las desigualdades posteriores serían producto de Dios o el mérito ${ }^{17}$.

15 PIIE (1984) denomina a estos elementos de continuidad como continuismo desarrollista (p. 102)

16 Señala El Ladrillo: "La política educacional debe estar encaminada a garantizar la igualdad de oportunidades a todos los ciudadanos de modo que cada cual pueda desarrollar al máximo su potencial humano" (CEP 1992, p. 145).

17 ODEPLAN (1983) ii. La responsabilidad del Estado en proveer el acceso a la educación. Ello se subentiende ya que en ningún momento se cuestiona este principio pero, como señalamos anteriormente, se concentra en la educación básica.

iii. La responsabilidad del Estado por los contenidos de la educación. Contrariamente a la propuesta de comienzos de la década de 1990, el rol del Estado es visto como centralizador y controlador de los contenidos educacionales, no solo por un principio de igualdad sino sobre todo por uno de control ideológico.

Entre los elementos rupturistas e innovadores se encuentran:

iv. La autolimitación de la acción estatal centralizada como agente proveedora de educación. Como señalamos anteriormente, la historia educacional chilena de la segunda mitad del siglo XX se había caracterizado por una creciente extensión del Estado centralizado como proveedor, garante y organizador del proceso educativo.

v. Consecuentemente con lo anterior, una innovación importante es la cesión de espacio en el mundo educativo escolar a los actores privados y la consecuente autorización para el lucro mediante la oferta educativa subvencionada. Tradicionalmente la actividad privada subvencionada en educación había estado fuertemente limitada en el país, situación que ahora se invierte. El lucro, por su parte, había sido algo absolutamente ajeno a la oferta educativa subsidiada.

Con todo, hay otros elementos que mirados a tres décadas de distancia continúan llamando la atención al momento de hacer un balance en el peso que se hizo de las innovaciones: en primer lugar, no queda claro el trasfondo de la crítica a la manera centralizada como había funcionado hasta ese momento la educación. Lo más elaborado -más allá del argumento de la "politización"- es lo relativo a una mayor eficacia en el gasto, pero a juzgar por la fuentes revisadas, no es este un argumento en el que se profundice demasiado, sino que más bien se argumenta, casi dogmáticamente, que una mayor 
La narrativa educacional chilena y su proceso de transformación reciente: un análisis sociológico-histórico

Javier Corvalán

desconcentración, descentralización y privatización educativa significaría un mejor uso de recursos. En la misma línea definitivamente no se proponen argumentos que avalen técnicamente los beneficios de tal desconcentración. Por lo mismo, la propuesta que se realiza parece en esencia una estrategia respecto de la crisis fiscal que se vivía en esos años ${ }^{18}$. En segundo lugar, no aparece claramente establecido el porqué del traspaso a los municipios y no, en su lugar, una propuesta de total privatización de los establecimientos educacionales.

En términos globales, el intento refundacional de la educación chilena llevado en la década de 1980 es, como en otras áreas de la vida pública y social chilena, un proyecto para generar una nueva narrativa, en este caso educacional, que apunta sobre todo a tres quiebres o transformaciones en relación a la narrativa construida en las décadas anteriores:

i. El primer elemento de quiebre es el relativo a la relación entre el Estado y la sociedad en relación a la generación de educación. Como hemos señalado esta provisión de educación en Chile, particularmente desde los años cuarenta, tuvo un discurso y una práctica fuertemente institucionalizada mediante profundos procedimientos y estructuras formales y estatales (regulación burocrática). Las alusiones a la participación e involucramiento de las familias se expresaban de preferencia en el sector privado y en particular en los establecimientos católicos. El régimen militar propone como parte de su política social y de su declaración de principios un énfasis en elemento de tipo familista y privatista que no estaba presente en las definiciones anteriores de la educación chilena. Por ejemplo, en el discurso de inauguración del año escolar 1987 se señala:

Familia y comunidad: como nunca antes lo hizo alguna anterior Constitución, pone la de 1980 el énfasis en la responsabilidad educacional en donde corresponde por Derecho Natural: en la familia y en su

18 La recesión internacional de 1982 hizo que el producto interno bruto del país cayera ese año en un $13,5 \%$. medio circundante nacional y local, constituido por la comunidad (Discurso del Ministro de Educación. Inauguración del año escolar 1987).

En esta misma línea hay un quiebre y una innovación importante de enormes consecuencias simbólicas dentro de la narrativa histórica de la educación chilena. Se trata del cambio de regulación o control del sistema educativo desde una institucionalidad (el Estado central) hacia un mecanismo (el mercado y en particular la demanda). Así, el nuevo discurso hará un giro de proporciones entre un Estado garante del servicio educativo (hasta el momento en lo que corresponde a su provisión y no a su calidad) y de sus características específicas, hacia una responsabilización de los individuos a partir de la racionalidad de sus acciones (la buena elección de establecimiento educacional). Por lo anterior, es posible sugerir que aquello que está en el fondo en esta transformación es precisamente un cambio en la gobernabilidad del sistema escolar. De esta manera, si frente a las preguntas de a partir de quién y cómo se gobierna este sistema surgían anteriormente las respuestas del gobierno central y sus mecanismos burocráticos, ahora la respuesta pasa a ser la comunidad local (en la figura del municipio) y más específicamente los individuos a partir de mecanismos de mercado y en especial, desde la demanda. Llama la atención que dentro de la justificación de este mecanismo no se hace alusión a la regulación de la calidad de la educación (recordemos que este término hace su aparición en la discusión educacional en la segunda mitad de los años ochenta) por lo que es posible hipotetizar que tal justificación se relaciona con una adecuación entre la demanda y la oferta del servicios educacionales, evitando así la mantención de establecimientos con baja asistencia. Al mismo tiempo este mecanismo busca asegurar la asistencia efectiva de los alumnos a los establecimientos ${ }^{19}$.

19 Con todo el tema de la medición de la calidad de la educación está presente en un periodo de ese gobierno bajo las iniciativas de la Prueba de Evaluación del Rendimiento Escolar (PER), a partir de 1982 y luego con la creación del Sistema de Medición de la Calidad de la Educación (SIMCE), en 1988. 
ii. Un segundo elemento de quiebre respecto de la relación entre el Estado y la sociedad civil respecto de la provisión de educación es lo que se refiere a la continuidad de estudios después de la enseñanza básica. En efecto, el desarrollo de la educación chilena hasta los años setenta había puesto el énfasis en el aumento de la cobertura y en el intento de universalización de la educación básica y media. Respecto de la educación superior aún cuando su cobertura a inicios de la década señalada era muy menor (en torno al 10\%), parte importante de sus políticas ponían el énfasis en un aumento socialmente equitativo de su matrícula. La transformación educativa de los años ochenta genera un profundo cambio al respecto lo cual queda graficado en los puntos 4 y 5 de la carta del general Pinochet al Ministro de Educación en marzo de 1979, documento que la prensa de la época tituló Aspectos Fundamentales de la Revisión del Proceso Educacional y que en los puntos referidos señala:

El Estado centrará el énfasis en la educación básica y a cualquier costo cumplirá su deber histórico y legal de que todos los chilenos no solo tengan acceso a ella sino que efectivamente la adquieran y así queden capacitados para ser buenos trabajadores, buenos ciudadanos y buenos patriotas; 5) Alcanzar la educación media $y$, en especial, la superior, constituye una situación de excepción para la juventud y quienes disfruten de ella deben ganarla con esfuerzo -lo cual implica un alto nivel de trabajo y exigencia compatibles con los avances científicos y tecnológicos- $\mathrm{y}$ además debe pagarse o devolverse a la comunidad nacional por quien pueda hacerlo ahora o en el futuro. El que reciba gratuitamente una educación que pueda pagar o no restituya el valor cuando esté ello a su alcance, priva de legítimas oportunidades a otros chilenos (El Mercurio, 1979). iii. El paso de una educación fiscal a una municipal, dado que durante los 80 todos los establecimientos educacionales del Estado fueron transferidos a las respectivas municipalidades. La respuesta a por qué se produjo este traspaso conduce necesariamente a estudiar la producción discursiva de la época y los análisis que se han hecho de ella. Los análisis del periodo en cuestión hacen factible establecer dos grandes polos orientadores de política a inicios de los ochenta. El primero es el referente del ya mencionado apoliticismo entendido de diversas maneras entre las cuales se destaca la primacía de intereses nacionales sobre los particulares y grupales y también una suerte de re-centramiento de instituciones tradicionales del país -entre ellas la educación- en torno a principios de los cuales se había alejado, tales como la formación de buenos ciudadanos a partir de la disciplina y los valores patrios. Esta ideología apolítica se relaciona con lo que Larraín denomina un proceso de refundación de identidad nacional en torno a la imagen del ejército en tanto institución apolítica y garante de la chilenidad (Larraín, 2005, p. 162).

El segundo polo orientador de políticas que se impone de manera paulatina en la segunda mitad de los años setenta y con decidida fuerza a inicios de los ochenta es lo que se ha denominado neoliberalismo, asumiendo todas las ambigüedades de este término, pero entendiendo que, para efectos de nuestro tema, se refiere a una priorización de los mecanismos de mercado en torno la gestión de áreas de política pública incluida la educación 20 tradicionalmente administradas a partir de otros principios. Otros análisis han clasificado de otra manera las explicaciones respecto del proceso de municipalización educativa durante el régimen militar argumentando orientaciones corporativistas y neoliberales como las

20 Sucintamente por mecanismos de mercado entendemos a procesos de coordinación de acciones a partir de: a) relación competitiva entre agentes; b) lucro o generación de ingresos a partir de criterios de eficiencia; c) priorización de oferentes privados y rol del Estado como garante de la relación entre estos y sus clientes. 
ya señaladas pero también las de tipo comunitariolocales, a las cuales nos referimos en los párrafos anteriores (Espinoza y González, 1993).

Ahora bien, la pregunta es entonces cómo la conjunción de ambas orientaciones ideológicas desemboca en una política educativa tendiente a la municipalización educacional y no, como parecería en principio más evidente, directamente a una privatización. Lamentablemente ni los documentos de la época ni los análisis posteriores entregan elementos que indiquen con claridad el lugar que ocupa la municipalización de la educación dentro del intento de generación de una nueva narrativa educacional y menos aún que permitan responder a la pregunta relativa a por qué no se produce un proceso definitivo de traslado de las escuelas hacia un sector particular subvencionado. Con todo, son tres las hipótesis que se pueden plantear al respecto: i) una cierta reticencia a entregar toda la educación a sectores privados puesto que, considerando el contenido ideológico propio de cualquier proceso educativo, dentro de tales oferentes potenciales de educación se encontraban sectores que podían no pertenecer a la matriz católica conservadora que formaba la Declaración de Principios del Gobierno y que como se señaló más arriba era asumida también como fundamento del sistema educacional 21 ; ii) un proyecto de control del proceso educativo puesto que además de lo aquí señalado, el Régimen Militar se inspiraba también en la llamada Doctrina de Seguridad Interior del Estado. No está de más recordar que el hecho de traspasar la educación a los municipios no implicaba necesariamente el desprendimiento del gobierno central del control de lo que en ellos sucedía. Por el contrario, los alcaldes eran un nombramiento directo del Jefe de Estado y, por consiguiente, la descentralización educacional bajo la estructura de la municipalización era un fenómeno que se restringía a los aspectos financiero-administrativos pero no al los de tipo político. El caso inverso se produce con

21 El gobierno de la época asume la noción de humanismo-cristiano como principio rector del sistema educacional pero dentro de tal acepción se incluía preferencialmente al catolicismo y dentro del mismo a interpretaciones del mismo cercanas o propias del régimen. el retorno a la democracia en 1990 momento en el cual, por primera vez en la historia reciente de la educación chilena y en el caso específico de los municipios cuyos alcaldes pertenecen a la oposición política, se rompe la cadena entre la orientación y definición política del gobierno central y la del poder inmediato que gobierna las escuelas municipales; iii) finalmente, y lo que se considera más cercano a esta problemática, la municipalización permite una continuidad histórica con la idea de educación pública arraigada después de medio siglo de expansión de la misma al amparo del Estado. Aún cuando el gobierno de la época evita hablar de educación pública propiamente tal (en los documentos analizados no encontramos el concepto salvo para referirse al período anterior a la transformación) sí genera un sistema educativo al amparo del Estado, si por tal se entiende al menos la garantía financiera del mismo. En este aspecto entonces el proyecto municipal en educación por parte de la dictadura refleja en cierto sentido asumir el peso histórico de la narrativa y la tradición educacional y por lo mismo da cuenta que el gobierno no estaba dispuesto a asumir los costos de su eliminación.

El proyecto de descentralización educativa en términos de municipalización fue, como en todo proceso político, un producto híbrido que buscó un consenso entre diferentes orientaciones presentes en el régimen imperante y que para su correcta comprensión es necesario apelar nuevamente al concepto de narrativa educacional. En efecto, si, como se acepta ampliamente, la orientación de desarrollo económico y social del régimen es nítidamente neoliberal transformándose tal orientación en un discurso que identifica el desarrollo y bienestar social con la maximización de la iniciativa privada orientada por el lucro, la disminución de las regulaciones entre los actores privados a lo estrictamente funcional, la visión negativa de la asociatividad de tipo reivindicativa y en su reemplazo por una asociatividad fundamentalmente expresiva, no hubiese cabido otra opción en este panorama que la privatización absoluta del sistema educacional público. Sin embargo, ello no fue así y en su reemplazo se llegó a este proyecto de municipalización que en varios 
de sus aspectos se encuentra a medio camino entre una educación pública y una privada.

En definitiva, una propuesta de privatización absoluta del sistema educacional hubiese sido la negación de una narrativa muy arraigada hasta ese momento, constituida durante décadas y asumida no solo por la población destinataria de la educación pública sino también por parte importante de los actores gobernantes. El elemento híbrido más notable en este diseño educacional es que genera un subsistema educacional al amparo de instituciones públicas y de naturaleza no mercantil como son los municipios pero que tal sistema asume reglas del juego propias de las entidades privadas y con fin lucrativo tales dentro de las cuales la más notoria es el acceso competitivo a los recursos a partir del nivel de demanda que les afecte, es decir, el conjunto de procesos que se desarrollan a partir de la subvención educacional.

\section{La narrativa educacional chilena a partir del retorno a la democracia. Elemento de debate}

En marzo de 1990 Chile retorna a la democracia bajo el gobierno de la Concertación de Partidos por la Democracia, coalición que se mantuvo en el poder hasta inicios del año 2010. El panorama en el cual la Concertación recibe la educación chilena es deficitario y políticamente adverso en la mayor parte de sus aspectos (MINEDUC, 1992) lo que justifica que las primeras iniciativas educacionales innovadoras sean de carácter compensatorio. Hacia la segunda mitad de los años noventa, se observa una fuerte legitimación de los elementos de medición educacional, en particular el SIMCE22, que influyen no solo en la gestión de las políticas educativas sino también en la introducción de un nuevo léxico para referirse al sistema educativo y, por tanto, impactan también en la narrativa del sector. Es este indicador, además, el que a comienzos de los noventa permite

22 Sistema de medición de calidad de la educación (www.simce. cl). Evaluación censal y estandarizada de la totalidad de alumnos chilenos en determinados grados escolares. Sus resultados se exhiben públicamente a nivel de promedios por establecimientos. Fue inaugurado a fines de la década de 1980 y perfeccionado y ampliado en sus usos y ámbitos de evaluación en las dos décadas siguientes. diagnosticar la profunda inequidad educacional y la baja calidad de los aprendizajes de los escolares chilenos (Comisión para el Desarrollo y Uso del Sistema de Medición de la Calidad de la Educación, 2003).

Probablemente sea el SIMCE el elemento que reúne más fehacientemente el encuentro entre las producciones discursivas de ambas narrativas educacionales. En efecto, el SIMCE tiene al menos tres interpretaciones: i) desde un discurso educacional plenamente anclado en el decenio de 1980, el SIMCE puede ser entendido como información al consumidor de educación a efecto que tome las correctas decisiones en el mercado educacional, es decir, que opte por exit, voice o loyalty ${ }^{23}$ a partir del establecimiento educacional que frecuenta o pretende frecuentar. Desde este punto de vista, el SIMCE sería una innovación absoluta en relación a la narrativa educacional centro-estatista ya que responsabiliza finalmente a los individuos por la calidad educativa de los establecimientos y del sistema educacional en su conjunto frente a la responsabilidad casi absoluta

23 Exit (salida), voice (voz) y loyalty (lealtad) es el título de un connotado libro del economista Albert Hirschman (1977) y que, precisamente, hace alusión a las tres posibilidades del individuo en un contexto institucional dispuesto como un mercado, en nuestro caso, de las familias frente a las escuelas. La salida es la conducta de fuga y de búsqueda de alternativas institucionales mejores, la voz se refiere a algo que no necesariamente está incorporado en las propuesta de organización mercantil de la política educativa y se relaciona con la capacidad expresiva de los individuos, bajo la forma ya sea de protesta o de propuesta al interior de la institución para producir mejoras en ella. Es la conducta de aquellos que no quieren abandonarla pero que tampoco están conformes con su situación actual. Por último, la lealtad se refiere a la conducta de permanencia y adhesión de aquellos que consideran que la institución es la mejor opción. Los análisis de la última (ver por ejemplo Corvalán y Román 2012) década respecto del sistema educacional chileno demuestran que para dar cuenta del mismo estas categorías deben al menos ser relativizadas: al parecer son pocos los que salen, dado que el cambio de establecimiento educativo es un tema complejo que involucra sobre todo aspectos subjetivos en juego (del propio alumno, principalmente); tampoco son tantos los que se expresan y tal expresión, cuando ocurre, no parece tener mayor impacto. Tomar seriamente el tema de la voz implica un diseño comunitario y participativo del sistema educacional lo que es contradictorio con la existencia de instituciones de naturaleza privada que no están obligadas a desarrollar la participación de la comunidad y es contradictorio también con una visión de mercado propiamente tal en el que los clientes no participan en el negocio del dueño, sino que simplemente si no están conformes, cambian de tienda. Por último, los que se quedan no necesariamente lo hacen por lealtad sino, muchas veces, por falta de opción. 
que del mismo tenía el gobierno central antes de los ochenta; ii) en contrapartida desde un discurso propio de los años noventa, el SIMCE es visto principalmente como un recurso orientador de políticas y por tanto como un instrumento que orienta y responsabiliza al Estado, al menos parcialmente, por los niveles de calidad y equidad imperante en el sistema educacional; iii) desde un punto de vista intermedio entre las dos primeras interpretaciones, el SIMCE es visto como información para el mejoramiento de los establecimientos, es decir, una suerte de apelación a un proceso de tipo comunitario-institucional en el que la unidad educativa pueda observarse diacrónicamente y proponer soluciones a sus áreas deficitarias siendo estas últimas apoyadas por el nivel local o nacional (cf. Bellei, 2002).

La producción discursiva del gobierno entrante en 1990 acentúa la idea de que la educación chilena se encuentra en una profunda crisis (cf. GarcíaHuidobro, 1989; Brunner y Cox, 1995; Cox 1993). Por otro lado y en el plano político, el día anterior al cambio de gobierno (10 de marzo de 1990) se promulga la Ley Orgánica Constitucional de Enseñanza (LOCE) que consagra el orden institucional de la educación chilena sellando, con rango constitucional, varios de los elementos rupturistas de los años ochenta, entre ellos los ya señalados de incentivo a la participación de los agentes privados en educación, la primacía dada a la libertad de enseñanza y la responsabilidad de la familia por la educación de sus hijos, incluyendo la elección de establecimiento (tema este último que no es novedoso en la educación chilena pero que se refuerza como elementos central de los derechos y responsabilidades familiares en educación). A nivel muy general, los nuevos referentes del discurso educativo al inicio de los noventa son los de calidad y equidad, en reemplazo (parcial al menos) de cobertura y acceso a la educación. Si bien ambos conceptos (calidad y equidad) son novedosos en términos de que ellos no estaban presentes en la narrativa centro-estatista ni en la de mercado o competitiva, lo que se hace a partir del año 1990 es integrar de mayor manera una responsabilidad estatal por el proceso y los resultados educativos (Cox, 2003).
Reconocemos entonces en nuestro análisis que la coalición gobernante en Chile a partir de los años noventa trata de generar una nueva producción discursiva en educación. Lo que no es totalmente claro es que esta sea una nueva narrativa y lo que no corresponde en absoluto afirmar es que se trate de una recuperación de la de tipo centro-estatista. Reafirmamos aquí lo señalado al inicio de este artículo en términos del peso histórico en los sistemas educativos lo que implica, por lo mismo, la imposibilidad de legitimar fácilmente cambios de tipo radical y que, al contrario, obligan por lo general a alternativas reformistas graduales.

Al parecer, este intento de fundación de una nueva narrativa educacional se produce al inicio de la década de 1990 con un discurso que está expresado en los llamados programas de mejoramiento (García Huidobro y Cox, 1999). Estos programas no son solo soluciones técnicas sino que sobre todo y desde el punto de vista de este texto, se trata de producciones simbólicas que sintetizan roles y obligaciones por parte del Estado en educación, y que comunican a la sociedad aquello que será considerado inaceptable dentro del orden educacional. Dos son los programas que instalan este nuevo discurso: el Programa de Mejoramiento para Escuelas de Sectores Pobres (P-900) y el Programa MECE (Mejoramiento de la Calidad y Equidad de la Educación); por motivos de espacio hacemos referencia solamente a este último. Sintéticamente y considerando los documentos oficiales de la época es posible formular cinco elementos que marcan tanto los objetivos del MECE como el centro de la nueva política educacional de los años noventa. Tres de estos elementos corresponden a aspectos considerados positivos o favorable para las nuevas iniciativas educacionales y otros dos son de carácter problemático:

a. El primero se refiere a un alto clima de consenso en el país respecto de la organización descentralizada del sector educación. Esto significa asumir un elemento propio de la política y de la generación discursiva de los años ochenta.

b. El segundo elemento -ya mencionado anteriormente- es el de la cobertura educativa: "el 
país ha dejado atrás el acceso a la educación como problema principal: prácticamente la totalidad de niños de 6-13 años está en la escuela y más de tres cuartas partes de los del grupo 14-17 es atendido en la educación media" (MINEDUC, 1992, p. 7). Se trata aquí de un elemento del discurso que busca situar la discusión política educativa en torno a nuevos referentes.

c. El tercero de estos elementos considerados positivos se basa en la situación y las perspectivas socioeconómicas del país. En efecto, el MECE asume la inminencia del paso del país a un mayor desarrollo económico y tecnológico en los próximos años, fenómeno para el cual la educación no está preparada. Se trata este de un discurso que se afirma fuertemente en la propuesta de CEPAL-UNESCO (1992) y de sus implicaciones en la formación de capital humano en el país.

Frente a estos elementos considerados positivos en el diagnóstico de inicios de los noventa, se plantean dos realidades negativas: la falta de calidad de los contenidos de la educación nacional y la escasa equidad en la distribución de los bienes educativos:

sin desafíos mayores respecto de los problemas de acceso a la educación, ni dilemas sobre la organización del sector, el núcleo de demandas de la sociedade respecto de su sistema educativo, así como el propio nivel de desarrollo alcanzado por este definen hoy en a la calidad de sus procesos internos y resultados, y la equidad de la distribución social de éstos, como el centro de la política educacional [...] una educación de pobre calidad limita en forme grave las posibilidades de obtener las metas consensuales de un orden social justo e integrado en su diversidad, de una democracia estable, y un crecimiento económico de bases sólidas. (MINEDUC, 1992, pp. 7, 8).

Es interesante observar cómo, durante la primera mitad de los años noventa se lleva a cabo esta nueva producción discursiva en educación, que reúne a otros programas importantes de la época y que solo hacia la segunda mitad de la década, específicamente en 1996, este proceso es denominado reforma educativa 24. Por último, resulta interesante también cómo en esta nueva producción discursiva hay un intento de recuperación de un rol estatal en educación -prácticamente inexistente durante el período dictatorial- y que, tal como se planteó en páginas anteriores, se le busca una armonización con las modificaciones estructurales de los años ochenta, en particular la descentralización del sistema educativo.

La movilización de estudiantes secundarios del año 2006 ("Revolución de los pingüinos", -cf. Bellei, Contreras y Valenzuela, 2010-) marca un quiebre en el estado de la discusión socio-educacional chilena y de acuerdo a las definiciones de este artículo, un intento de cambio en la narrativa educacional imperante. Esta movilización instaló al menos tres temáticas en la conversacional nacional sobre la educación: a) lo inaceptable de la desigualdad educacional persistente en el país después de una década y media de implementación de estrategias de solución a tal problema; b) el fin del carácter lucrativo de instituciones educativas financiadas con recursos estatales; c) una mayor injerencia y responsabilidad del Estado por la gestión y los resultados educacionales.

$\mathrm{Al}$ analizar cada uno de estos temas vemos que ellos corresponden en gran medida a los contenidos básicos de la narrativo-centro-estatista de la educación chilena existente hasta la década de 1970, con algunas variantes. En efecto, la crítica a la desigualdad educacional era algo ya presente a partir de la mitad del siglo pasado concretizada en el ideal de la plena cobertura en la educación básica. La variante que la movilización estudiantil del año 2006 introdujo en esta aspiración un acento en la calidad de los resultados educativos, es decir, se recoge parte de la problematización de las políticas educacionales de los años noventa en adelante, que no enfatizan tanto en la cobertura, meta ya lograda al menos a nivel básico, sino en los distintos efectos que la asistencia a la escuela tiene en los alumnos dependiendo del origen social de los mismos.

24 Específicamente en el Discurso Presidencial del 21 de mayo de 1996. 
El segundo tema, la crítica al lucro en educación, es algo que ya estaba presente de manera tácita en la antigua narrativa educacional, ya que la legislación imperante no permitía que los establecimientos privados que recibían subvención del Estado tuviesen una finalidad mercantil. Curiosamente este tema es al menos parcialmente modificado por la legislación instalada a comienzos de los años ochenta, específicamente en lo relativo a la educación superior, por cuanto en ella se incentiva la creación de nuevas universidades privadas pero dentro de un marco también no lucrativo, aun cuando no reciban subsidios de Estado. Con ello se propone que el gobierno de la época conserva y reafirma, al menos parcialmente, la idea de la antigua narrativa educacional que establecía una contradicción entre la educación y el lucro. Es posible establecer también que la manera en que el movimiento estudiantil expresa su rechazo al lucro en educación implica una crítica a la regulación de mercado y competitiva en el sistema educacional, más allá del tema específico del lucro. Dicho de otro modo, este último tema encapsula y sintetiza una crítica global más amplia a aspectos considerados inaceptables en el funcionamiento del sistema educacional.

Por último, el tema de la mayor ingerencia y participación del Estado en la gestión del sistema educacional es, al parecer, un elemento que marca la argumentación central de este artículo. En efecto, a partir de la movilización estudiantil del año 2006 se generan las críticas y demandas que reseñamos en los puntos anteriores y que el discurso de quienes reivindican los cambios centra en el Estado tanto como responsable de dicha situación como en la obligación de actuar para solucionarla. En consecuencia, el centro de la producción discursiva de la movilización estudiantil da cuenta de la permanencia de la narrativa educacional centro-estatista, en tanto gran parte de las medidas propuestas a partir de ella se ubican, paradojalmente, desde la narrativa competitiva (cf. Bellei, Contreras y Valenzuela, 2010). Algo similar ocurrió con un último fenómeno y que aquí solo tenemos el espacio para reseñar, nos referimos a la movilización de estudiantes de educación superior ocurrida en 2011 en Chile. Se trata esta de la más importante de las movilizaciones de este nivel de estudiantes que se tenga memoria desde el regreso a la democracia y cuyas banderas de lucha, aun cuando centradas la mayor parte de ellas en el ámbito universitario, recogen el ideario propuesto por la movilización del año 2006 y que de acuerdo al concepto central de este artículo, abogó por políticas educacionales que se sustenten en la recuperación de aspectos fundamentales de la narrativa centro-estatista o por lo menos de una que confronte los principales supuestos de una narrativa de tipo competitiva y mercantil en educación.

\section{Conclusión}

La discusión de la última década en Chile sobre el sistema educacional y sus necesarias transformaciones se ha planteado reiterativamente como un debate técnico en el cual el centro de la discusión, parece ser, el descubrimiento de la solución más eficiente a problemas que se manifiestan como evidentes. Sin embargo, es importante recordar que la educación es también un tema ideológico y simbólico que existe como representación y aspiración colectiva de la ciudadanía, que tales representaciones han sido construidas a través de la historia educacional de cada sociedad así como por los discursos públicos que se han generado y legitimado en torno a esa historia. Si bien en las últimas décadas se ha insistido en Chile en un concepto de educación que la define desde un punto de vista técnico e individual -identificándola de manera casi total con la teoría del capital humano- en los discursos de los actores, y particularmente en las movilización estudiantiles de los años 2006 y 2011, se observa una representación de la educación cercana a una idea de profundización democrática, de construcción de un colectivo, de integración social, y de crítica a las soluciones de mercado y de tipo competitiva en educación, entre otros aspectos. Tal vez sea cierto decir que una narrativa centro-estatista esté superada en la educación chilena; sin embargo, tampoco parece evidente que en su reemplazo se haya instalado una que reniegue del Estado y que abrace totalmente un concepto de educación entendida solo como capital humano. 


\section{Referencias bibliográficas}

Anderson, B. (1993). Comunidades imaginadas. Reflexiones sobre el origen y la difusión del nacionalismo. Buenos Aires: Fondo de Cultura Económica.

Archer, M. (1984). Social origins of educational systems. London: Sage.

Bellei, C.; Contreras, D. y Valenzuela, J.P. (eds.) (2010). Ecos de la revolución pingüina. Santiago de Chile: Universidad de Chile, Unicef.

Barros, D. (1902). Historia jeneral de Chile. Santiago de Chile: Imprenta Cervantes.

Becker, G. (1983). Capital humano. Madrid: Alianza.

Bellei, C. (2002). Apuntes para debatir el aporte del SIMCE al mejoramiento de la educación chilena. Recuperado el 30 de octubre de 2011 de: http://www.piie.cl/ centro-de-documentacion/images/pdf/PolRefEdu/ Apuntes\%20para\%20debatir\%20el\%20aporte\%20 del\%20SIMCE.pdf

Bourdieu, P. y Passeron, J.C. (1970). La réproduction. Élements pour une théorie du système d'énseignement. Paris: Minuit.

Bourdieu, P. (1979). La distinction. Critique sociale $d u$ jugement. Paris: Minuit.

Brunner, J.J. (1980). Sociología de los principios educativos. Un análisis de dos reformas de los planes y programas de la enseñanza básica chilena: 1965 y 1980. Santiago de Chile: Flacso.

Brunner, J.J. y Cox, C. (1995). Dinámicas de transformación en el sistema educacional de Chile. En J. Puryear y J.J. Brunner. Educación, equidad y competitividad en las Américas. Un proyecto del diálogo interamericano (pp. 101- 152). Vol. II. Estudios de caso. Washington: OEA.

Cepal-Unesco, 1992, Educación y conocimiento: eje de la transformación productiva con equidad. Santiago de Chile: Cepal-Unesco.

Comisión para el Desarrollo y Uso del Sistema de Medición de la Calidad de la Educación (2003). Evaluación de aprendizajes para una educación de calidad, Santiago. MINEDUC.

Corvalán J. y Romám. M. (2012) La permanencia de escuelas de bajo rendimiento crónico en le cuasi mercado educativo chileno. Revista Uruguaya de Ciencia Política 21(01), 43-64.
Corvalán, J.; Elacqua, G. y Salazar, F. (2010). El sector particular subvencionado en Chile. Santiago de Chile: MINEDUC.

Cox, C. (1993). Las políticas de los 90 para el sistema escolar. Santiago de Chile: MINEDUC-MECE.

Cox, C. (2003). Las políticas educacionales de Chile en las últimas dos décadas del siglo XX. En C. Cox (ed.). Políticas educacionales en el cambio de siglo. La reforma del sistema escolar en Chile (pp. 19 -114). Santiago de Chile: Editorial Universitaria.

Durkheim, E. (1972). La educación moral. Buenos Aires: Shapire.

Durkheim, E. (1982). Historia de la educación y de las doctrinas pedagógicas. La evolución pedagógica en Francia. Madrid: La Piqueta.

Durkheim, E. (1990). Educación y sociología. Barcelona: Península.

Egaña, M.L. (2000). La educación primaria popular en el siglo XIX en Chile: una práctica de política estatal. Santiago de Chile: Centro de Investigaciones Diego Barros Arana, DIBAM, PIIE, LOM.

El Mercurio (8 de marzo de 1979). Carta de S.E. al Ministro de Educación, 5 de marzo de 1979. Aspectos Fundamentales de la Revisión del Proceso Educacional. Primer cuerpo p. 1

El Mercurio (1 de junio de 1980). "Entrevista al presidente Pinochet”. Segundo cuerpo p.2.

Espinoza, O. y González, L.E. (1993). La experiencia del proceso de desconcentración y descentralización educacional en Chile 1974-1989. Santiago de Chile: PIIE. Recuperado de: http://www.piie.cl/documentos/ documento/descentralizacion_oscar_espinoza2.pdf

García-Huidobro, J.E. (ed.) (1989). Escuela, calidad e igualdad. Santiago de Chile: CIDE.

Garcì-Huidobro, J.E. y Cox, C. (1999). La Reforma Educacional Chilena 1990-1998. Visión de conjunto. En J.E. García-Huidobro (ed.). La Reforma Educacional Chilena (pp. 7-46). Madrid: Editorial Popular.

Garretón, M.A. (1983). El proceso político chileno. Santiago de Chile: Flacso.

Garretón, M.A. (2005). Las Ciencias Sociales en Chile. Institucionalización, ruptura y renacimiento. Recuperado el 7 de noviembre de 2011 de: http://www. insumisos.com/lecturasinsumisas/Ciencias\%20 sociales\%20en\%20Chile.pdf

Hirschman, A. (1977). Salida, voz y lealtad. México: Fondo de Cultura Económica. 
Labarca, A. (1939). Historia de la enseñanza en Chile. Santiago de Chile: Imprenta Universitaria.

Larraín, J. (2005). ¿América Latina moderna? Globalización e identidad. Santiago de Chile: LOM.

Larraín, J. y Larraín, J. (1871). Boletín de las principales leyes y decretos vijentes dictadas desde enero 1 de 1860 hasta enero 1 de 1871 y recopiladas por orden de materias. Valparaiso: Imprenta de El Mercurio.

Linblad, S. y Popkewitz, T. (2001). Education governance and social integration and exclusion. Studies in the power of reason and the reason of power. A report of EGSIE project. Uppsala: Departament of Education, Uppsala University.

Linblad, S. y Popkewitz, T. (eds.) (2004). Educational Restructuring. International Perspectives on Educational, Policy, Research and Practice. Greenwich: Information Age Publishing.

Ministerio de Educación (1961). Bases generales para el planeamiento integral de la educación chilena. Santiago de Chile: MINEDUC.

Ministerio de Educación (1964). Algunos antecedentes para el planeamiento integral de la educación chilena. Santiago de Chile: MINEDUC.

Ministerio de Educación (1992). Orientaciones básicas, objetivos y componentes del programa MECE. Santiago de Chile: MINEDUC.

Núñez, I. (s.f.). Tradición, reformas y alternativas educacionales en Chile, 1925-1973. Santiago de Chile: Estudios Vector 1.

Núñez, I. (1989). Historia del trabajo y formación de profesores en Chile. Santiago de Chile: PIIE.

Núñez, I. (1997). Historia reciente de la educación chilena. Recuperado el D15 de noviembre de 2011 de: http:// historiaeducacion.tripod.com/sitebuildercontent/ sitebuilderfiles/historia_reciente.doc

Núñez, I. (1998). El Ministerio de Educacion de Chile: instrumento del rol estatal en educación 1927-1997. Recuperado el 15 de noviembre de 2011 de: http:// www.piie.cl/centro-de-documentacion/images/pdf/ PolRefEdu/HISTMINponIVC.pdf

Odeplan (1983). Informe social. Santiago de Chile: Odeplan.

Parsons, T. (1959). The school class as a social system: Some of its functions in american society. Harvard Educational Review, 29(4), 297-318.

Parsons, T. (1988). El sistema social. Madrid: Alianza Editorial.
Programa Interdisciplinario de Investigaciones en Educación (1984). Las transformaciones educaciones del Régimen Militar. Santiago de Chile: PIIE.

Ruiz, C. (2010). De la república al mercado. Santiago de Chile: LOM.

Serrano, S. (1994). Universidad y nación. Chile en el siglo XIX. Santiago de Chile: Universitaria. 